Article

\title{
A New Model for Inclusive Sports? An Evaluation of Participants' Experiences of Mixed Ability Rugby
}

\author{
Martino Corazza ${ }^{1, *}$ and Jen Dyer ${ }^{2}$ \\ ${ }^{1}$ International Mixed Ability Sports, Bradford Deaf Centre, Bradford, BD1 3RP, UK; E-Mail: m.corazza@mixedabilitysports.org \\ 2 Sustainability Research Institute, University of Leeds, Leeds, LS2 9JT, UK; E-Mail: j.dyer@leeds.ac.uk \\ * Corresponding author
}

Submitted: 6 February 2017 | Accepted: 6 April 2017 | Published: 29 June 2017

\begin{abstract}
Sport has been recognised as a potential catalyst for social inclusion. The Mixed Ability Model represents an innovative approach to inclusive sport by encouraging disabled and non-disabled players to interact in a mainstream club environment. However, research around the impacts of the Model is currently lacking. This paper aims to contribute empirical data to this gap by evaluating participants' experiences of Mixed Ability Rugby and highlighting implications for future initiatives. Primary qualitative data were collected within two Mixed Ability Rugby teams in the UK and Italy through online questionnaires and focus groups. Data were analysed using Simplican et al.'s (2015) model of social inclusion. Data show that Mixed Ability Rugby has significant potential for achieving inclusionary outcomes. Positive social impacts, reported by all participants, regardless of (dis)ability, include enhanced social networks, an increase in social capital, personal development and fundamental perception shifts. Factors relevant to the Mixed Ability Model are identified that enhance these impacts and inclusionary outcomes. The mainstream setting was reportedly the most important, with further aspects including a supportive club environment and promotion of self-advocacy. A 'Wheel of Inclusion' is developed that provides a useful basis for evaluating current inclusive sport initiatives and for designing new ones.
\end{abstract}

\section{Keywords}

disability; inclusive sports; Mixed Ability Model; rugby; social inclusion; social networks; sport

\section{Issue}

This article is part of the issue "Sport for Social Inclusion: Questioning Policy, Practice and Research", edited by Reinhard Haudenhuyse (Vrije Universiteit Brussel, Belgium).

(C) 2017 by the authors; licensee Cogitatio (Lisbon, Portugal). This article is licensed under a Creative Commons Attribution 4.0 International License (CC BY).

\section{Introduction}

Sport initiatives are increasingly being viewed and promoted as catalysts to achieving a range of non-sporting objectives variously labelled under sport for social change or development (Edwards, 2015; Levermore \& Beacom, 2009), sport for peacebuilding and reconciliation (Rookwood \& Palmer, 2011; Sugden, 2006) and sport for education, equality and inclusion (EC, 2010; Kelly, 2011). The UN recognises the vital role sport can play in enhancing personal and societal development (UN, 2015) and the EU has been at the forefront of promoting the use of sport in combating exclusion, inequal- ities, racism and xenophobia (EC, 2010). As such the role of sport in promoting social inclusion has become a key focus in both research and international policy (Spaaij, Magee, \& Jeanes, 2014). However, there are calls for empirical evidence to show how the design and structure of projects and initiatives impact on positive social outcomes (Rich, Misener, \& Dubeau, 2015) and for community level research to develop localised theoretical frameworks to inform initiatives going forwards (Edwards, 2015). This research aims to contribute empirical evidence to these areas by analysing the implications of the Mixed Ability Model (hereafter MA Model) for inclusive sport through the evaluation of disabled and non- 
disabled participants' experiences of Mixed Ability Rugby (hereafter MA Rugby) in the UK and Italy. The MA Model seeks to promote social inclusion through the integration of disabled players into a mainstream social sport setting in their local community, playing alongside non-disabled participants. This research answers calls for better understanding of participant experiences and perspectives of inclusive sport (Levermore, 2010; Rich et al., 2015) and in particular hearing the voices and viewpoints of people with disabilities (Wickman, 2015).

\section{Sport and Inclusion}

\subsection{Sport and Disability}

Participation in sport and physical activities has been reported to have positive impacts in achieving personal and societal benefits, leading to a plethora of policies and initiatives promoting sport (Armour, Sandford, \& Duncombe, 2013; Bailey et al., 2009). In particular, these are targeted at underrepresented and traditionally marginalised groups. Disabled people fall into this category. In England, only 17\% of disabled people aged 16+ participate in sport for 30 minutes a week compared to $36 \%$ of non-disabled people (Sport England, 2016) and in Italy the gap is even wider, with only $15 \%$ of disabled people participating compared to $42 \%$ of the non-disabled population (ISTAT, 2010).

Article 30 of the United Nations Convention on the Rights of Persons with Disabilities encourages and promotes 'the participation, to the fullest extent possible, of persons with disabilities in mainstream sporting activities at all levels' (UN, 2006). However, the disability sports literature highlights a plethora of barriers remaining to this being acheived. Physical barriers are cited as lack of time, finances, carers/assistants, adequate infrastructure, transport and equipment (Darcy \& Dowse, 2013; EFDS, 2012) and emotional barriers include feelings of stigmatisation and exposure to prejudice (Wilson, Jaques, Johnson, \& Brotherton, 2016), lack of confidence and self-esteem, challenges around interpersonal communications and lack of awareness of opportunities and realistic role models (Darcy \& Dowse, 2013; EFDS, 2012). In line with the social model of disability, inclusive sports seek to focus attention on removing these 'disabling barriers' through emphasising societal interventions which enable disabled people to fully participate in sport and the broader community (Darcy \& Dowse, 2013; Swain, French, Barnes, \& Thomas, 2014). This leads to a more nuanced approach to sport delivery which recognises the multi-faceted experiences of every participant.

A growing body of literature examines the factors impacting the inclusive nature of sports. Positive outcomes appear more likely when emphasis is placed on participants understanding the project rather than being passive recipients of instruction (Petitpas, Cornelius, Van Raalte, \& Jones, 2005). Ensuring participants have roles and responsibilities, equal status and common goals also appear important (Edwards, 2015) as does the promotion and facilitation of friendship development (EFDS, 2014; Van Asselt, Buchanan, \& Peterson, 2015). In addition, encouraging participants to feel a sense of ownership within a sporting initiative has been found to optimise social inclusion (Darcy, Maxwell, Edwards, Onyx, \& Sherker, 2014; Van Asselt et al., 2015) and therefore more inclusive outcomes are likely to arise when the development of the initiative is led by participants rather than being imposed (Wendel et al., 2009).

\subsection{The Mixed Ability Model}

The MA Model represents an innovative approach to inclusive sport by integrating disabled players into a mainstream sport setting whether as players or participating in other ways such as organisational or educational roles. The Model grew organically from a lack of provision for disabled participants to play full-contact rugby. Unlike most sports provision for disabled participants, classification and identification systems are not used and MA Rugby is governed by World Rugby Laws without adaptation and with only minor adjustments to take into account individual participant needs. The MA Model has been developed, and is being championed by, IMAS (International Mixed Ability Sports), a community interest company who support grassroots clubs in establishing MA Rugby teams and who have co-produced educational resources with the participants of MA Rugby. Through this approach, IMAS seek to increase sustainable participation in sport, break down barriers between nondisabled and disabled participants, address social exclusion and generate long-term positive change. However, research into the MA Model is currently lacking, as is broader research into inclusive sports which encourage disabled and non-disabled participants to play collaboratively in a mainstream environment.

\subsection{Evaluating Social Inclusion}

Much research has gone into trying to pin down the complex concept of social inclusion. Cobigo, OuelletteKuntz, Lysaght and Martin (2012, p. 76) suggest that social inclusion should encompass 'full and fair access to community-based resources and activities, having relationships with family, friends and acquaintances and having a sense of belonging to a group' as well as representing participation in mainstream society rather than just presence. Simplican et al. (2015, p. 22) suggest social inclusion is the dynamic interaction of two core life domains which encompass the 'structural and functional components behind social inclusion' (Figure 1). The Interpersonal Relationships domain takes into account the variety of relationships in a social network (Category), the structural components of these relationships, such as frequency, location, reciprocity and complexity (Structure), and the levels of emotional, informational and instrumental support they provide (Function). The Com- 


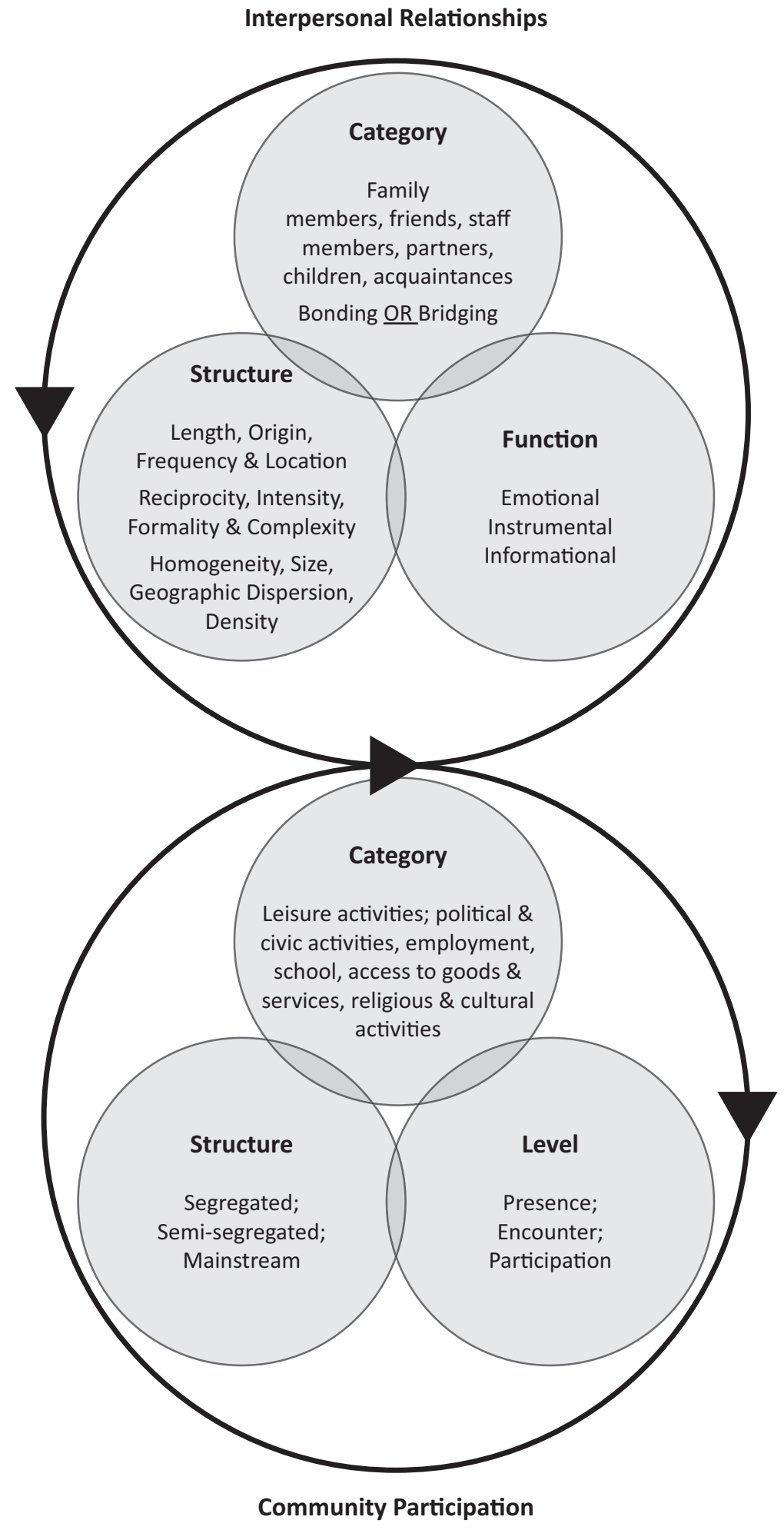

Figure 1. Simplican et al.'s (2015) model of social inclusion.

munity Participation domain captures types of community activities participants are involved in such as sporting, civic and cultural (Category), the setting of these activities, whether segregated, semi-segregated or integrated (Structure) and the potential for interpersonal relationship development, whether presence, encounter or participation (Level). The arrows on the model show how the two domains overlap and 'mutually support' each other. For example, increased participation in community activities may result in stronger and more diverse social networks and interpersonal relationships which may then result in further potential for community participation.

We explore the feedback within and between the two domains through the evaluation of participant experiences of MA Rugby, which sits within the Category 
component of the Community Participation domain. In using the model, we seek to map the relationships between community involvement in sport and the other components such as the impact of participation on interpersonal relationships and social networks.

\section{Research Design and Methods}

In order to evaluate participants' experiences of MA Rugby, two case studies were chosen: Chivasso Rugby (Italy) and Bumble Bees RFC (UK). These clubs were purposively selected as having well-established MA Rugby teams founded in 2009, and working closely with IMAS to develop educational resources and awareness around the MA Model through qualified specialist tutors in each club. In the UK context, there is also an 'Inclusion in Rugby' class which meets each week and is co-funded by the Workers Educational Association. Data collection took place between March and June 2016. A semistructured, online questionnaire was employed with nondisabled participants and others involved in MA Rugby, and supported focus groups were carried out with disabled participants in order to overcome potential barriers with IT and to allow time and support for articulation of their views.

The online questionnaire comprised 20 open questions. The questions were divided into: 1 ) respondent background and demographics, 2) personal experiences of MA Rugby and disability, 3) personal and communitylevel impacts of the MA Model and 4) exploring the characteristics of MA Rugby such as structure and setting. One focus group was held with 7 participants in each Club, allowing the gathering of individual in-depth answers, group discussions and general observations. The focus groups were structured around the same questions as the online questionnaire.

\subsection{Sampling}

Participants were selected for the study according to three criteria: 1) currently registered with their MA Club, 2 ) over 17 years old and, 3) having at least one year experience of MA Rugby. There were 82 potential participants: 37 and 45 in the UK and Italy respectively. 38 participants volunteered to join the study and their key attributes are summarised in Table 1. Respondents were asked for their primary role within the Club as well as other roles they play. Primary roles (and their analysis code) included non-disabled players/facilitators (F), disabled players $(P)$ volunteers $(V)$, referees $(R)$, Club doctor (D) and supporters (S) with additional roles including coaches, committee members, photographer and Team Manager. The respondent demographics reflect the prevalence of males given that National Governing Body rules state that females cannot play mixed gender, full-contact rugby.

\subsection{Analysis}

Respondents' questionnaire responses were downloaded into an excel document and assigned codes according to their country, primary role in their Club, gender and age (e.g. IFM55 would refer to a 55 year old male facilitator from Chivasso Rugby). Focus groups were transcribed and translated before both data sets were subjected to content analysis using a basic inductive method (Miles \& Huberman, 1994) and then according to Simplican et al.'s (2015) model of social inclusion. Re-

Table 1. Summary of online questionnaire respondent demographics.

\begin{tabular}{|c|c|c|c|}
\hline Characteristic & Details & Italy (19 respondents) & UK (19 respondents) \\
\hline \multirow[t]{2}{*}{ Gender } & $\mathrm{M}$ & 17 & 18 \\
\hline & $\mathrm{F}$ & 2 & 1 \\
\hline \multirow[t]{6}{*}{ Age } & $<18$ & 2 & 0 \\
\hline & $18-25$ & 6 & 4 \\
\hline & $26-35$ & 2 & 6 \\
\hline & $36-49$ & 5 & 4 \\
\hline & $50-64$ & 4 & 4 \\
\hline & $>65$ & 0 & 1 \\
\hline \multirow[t]{2}{*}{ Identify themselves as being disabled } & Disabled & 7 & 8 \\
\hline & Non-disabled & 12 & 11 \\
\hline \multirow[t]{3}{*}{ Years involved in MA Rugby } & $1-2$ & 10 & 5 \\
\hline & $3-5$ & 6 & 10 \\
\hline & $>5$ & 3 & 4 \\
\hline
\end{tabular}


curring themes were further interrogated and excerpts and quotes from questionnaires and focus groups were highlighted. This approach allowed for a broad narrative to emerge as well as providing enough detail for us to reflect the multi-faceted experiences of individual participants. The scope of this research did not allow for the thorough exploration of broader contextual factors, although note was taken where responses differed between the perspectives of participants from the different national case studies.

\section{Results}

Analysis of participant experiences revealed that MA Rugby had a broad range of positive impacts at the individual, Club and broader community-level. Data also highlighted dynamic relationships between the various components and domains of Simplican et al.'s (2015) model. With MA Rugby sitting within the Category component of the Community Participation domain, our data suggest that this component impacts on, in particular, the Category component of the Interpersonal Relationships domain. However, these impacts are facilitated and mediated by the other components of the model through the way MA Rugby is designed and organised.

\subsection{Impacts of Mixed Ability Rugby}

\subsubsection{Social Networks and Capital}

Respondents from both countries repeatedly identified that the biggest impacts of MA Rugby are developing new friendships, relationships and social networks. Bonding relationships were evident through teammates forging close friendships both on and off the rugby pitch. Respondents reported a sense of belonging and the word 'family' recurred 27 times:

...it's incredible because everyone is just himself, no one is afraid of being judged. It's like being a family. (IPM23)

There are only benefits for those who are part of it. It feels like being part of a new family. (UKFM53)

Participants from the UK emphasised even more clearly the value of bridging relationships between groups that would not traditionally meet and, in particular, between disabled and non-disabled participants:

[MA Rugby has impacted me] in a massively positive way...leading to many new friendships and relationships with people with and without disabilities. (UKSM51)

I have Asperger Syndrome. It's hard for me to communicate but now I'm part of a team and socialise in the bar after training and games. (UKPM41) ...for the vast majority it helps by including a whole new group of players, re-engaging former players and engaging the club with the community. (UKPM49)

This latter quote highlights the broad reach of MA Rugby. Participants reported getting involved through, for example, disabled family members, existing club members, work-related roles and service providers. Bridging relationships represented occasions for personal development amongst participants such as through external qualifications in coaching and paid employment and work experience through rugby contacts and through IMAS introductions and opportunities. Participants involved in the educational aspect of MA Rugby in particular, reported improved confidence, communication skills, professionalism and pride in their various roles as peer educators, Ambassadors and role models, teaching others how to play MA Rugby, creating and disseminating accessible National Governing Body resource packs and delivering co-produced equality awareness training. One facilitator summed up the reciprocal relationship between disabled and non-disabled participants:

Disabled players have become more confident in their own abilities and non-disabled players have become more confident in being with disabled people. (UKFM51)

\subsubsection{Shift in Perceptions}

The interaction between participants of MA Rugby was repeatedly revealed to have created a fundamental shift in perceptions among all participants. Many nondisabled participants reported an initial sense of curiosity, awkwardness and caution, as well as scepticism towards the MA Model, for example by confessing to not knowing 'how to interact with [disabled players]' (IFM55), and being 'not sure what to expect' (UKFM47). Many reported being apprehensive and one facilitator claimed he was worried about injuring disabled players (UKFM58). However, after being involved with the initiative, participants reported:

The biggest impact on me has been the change in my attitude to all people I come across now....I do not worry about whether I'm saying or doing the right thing....I see the person first. (UKFM49)

Disabled participants also reported undergoing perception shifts, both in the perception of non-disabled people, in particular through their interaction with facilitators, but also in self-perception:

The first time I joined the group, I thought of myself as different...I felt like out of context....And now, step by step, with my acquired new skills and abilities, I'm learning to realise that I can do more things than I thought. (IPM36) 


\subsection{Characteristics of MA Rugby}

\subsubsection{A Mainstream Setting}

When asked about the characteristics of MA Rugby that led to these positive impacts, responses from disabled participants overwhelmingly focused on the mainstream setting, aligning to the Structure component of the Community Participation domain in Simplican et al.'s (2015) model. All focus group participants stated that they enjoy MA Rugby because it is 'simply rugby' and challenged the idea that disabled people shouldn't be allowed to take risks, get injured or play contact sports. Participants acknowledged the risk of injury as something that can happen in life and as a decision they are entitled to make:

Rugby is about tackles and physical contact. We want to play it as it is. We accept the risk. (IPM21)

Disabled participants felt their disabled status faded into a wider sense of equality and being part of a team when playing. Indeed UK participants rejected wearing bibs to make the opposition aware of their disability as would be the case in most integrated sport settings. Facilitators recognised the power of this self-advocacy:

When we first started playing we put [disabled people] in bibs. They wore them a couple of times and then took them off saying, 'I don't want to wear them, it makes me stand out. I don't want to stand out, I want to be a part of the team'. (UKFM60)

The mainstream setting was also reported to further the social benefits of participating through access to Club facilities such as the bar, creating a positive feedback loop with the development of social capital and networks and aligning with a level of community participation that actively promotes the development of interpersonal relationships (Simplican et al., 2015). Being full members of their Club also affords financial sustainability and means regular activities such as tours can be funded. One participant highlighted that he had been on tour twice without his 'staff' which had further increased his sense of independence.

\subsubsection{A Supportive Environment}

Respondents highlighted that the supportive nature of the mainstream club environment was crucial to maximising positive impacts for participants. Many respondents, both disabled and non-disabled, reported how welcome and valued they had felt in joining:

It is a unique experience. I felt welcomed and important despite never having played rugby before. (UKPM26)

For disabled players, this often contrasted markedly from previous experiences of sports clubs:
I supported my local [rugby league] team for years. They would not let me play. The only thing I could do was to carry water bottles. They were afraid I could get injured. Of course I can get injured, it's part of the game. And since I joined the Bumbles I have snapped my Achilles, done my ligaments and I still want to play. (UKPM37)

When I retired from powerlifting I went to my local rugby club. They say they didn't have any other disabled players and that they couldn't help me. (UKPM36)

Many non-disabled participants recalled being impressed with the atmosphere, the focus on showcasing all abilities and the sense of value placed on everyone:

...those with learning or physical difficulties were treated and respected (and teased!) in exactly the same way as anyone else in the club. (UKSM60)

This supportive atmosphere has also encouraged returners to rugby, for example after injury or having given the sport up when they were younger. One UK returner got involved through a client and subsequently introduced another three contacts to the Club. He reported:

I am more confident and relaxed about being accepted and integrated by the group, they all make me feel part of the team, and they teach me the joy of the game. (UKFM59)

Further supportive elements for disabled participants were identified as involving carers, parents and support organisations in Club activities as well as providing participants with reminder slips for times, dates and logistics of training sessions and matches.

\subsubsection{Structural Components}

The frequency and consistency of weekly training sessions and regular matches, aligning to the Structure component of the Interpersonal Relationship domain of Simplican et al.'s (2015) model, reportedly meant that relationships were constantly developed and organisation of logistics improved, leading to further increases in confidence and independence in disabled participants. The location of training and matches at mainstream clubs endorses these feelings of independence, belonging and acceptance in the community. UK respondents in particular, referred to the Club as being 'well-known' and 'well thought of' in the local community for their rugby and also their 'ambassadorial skills'. One Club doctor stated:

Playing the Bumble Bees has made [my local Club] better and reconnected them to the reasons they play rugby: The enjoyment and the values. (UKDM63) 


\subsection{Challenges of MA Rugby}

Despite an overwhelmingly positive response from disabled and non-disabled respondents to participation in MA Rugby, there were also challenges raised. Two participants commented on the exclusion of females due to the mainstream nature of MA Rugby and adherence to World Rugby Laws and one female volunteer stated that she felt less involved in the social side given that there are fewer women to socialise with and much of the camaraderie is built on the pitch and in the changing rooms. These responses highlight the tension inherent in calling MA Rugby an inclusive sport when some groups are excluded. However, one participant commented:

So far [MA Rugby is] overwhelmingly male. But then again, so is mainstream rugby so I hesitate to criticise mixed ability alone for having a lack of opportunities for girls and women. (UKSM60)

Participants also highlighted that those with profound disabilities and in wheelchairs are thus far unable to play MA Rugby due to the terrain, although they are still encouraged to be involved in organisational and educational roles. Concerns were raised by Italian respondents over insurance issues as disabled participants are currently unable to be covered by the Italian Rugby National Governing Body as is the case in the UK. Respondents stated that this leaves disabled people vulnerable if they were to get seriously injured. In addition, some facilitators commented on the delicate balance between 'winning matches and not taking it all too seriously' (UKPM49) and one referee challenged the concept of keeping play fully inclusive:

I totally get the desire for all concerned for this to be wholly inclusive however.... am not entirely sure this is fully possible. (UKRM51)

\section{Discussion}

The analysis of participants' experiences show that MA Rugby meets the criteria of social inclusion put forward by Cobigo et al. (2012) in that it promotes full and fair access to community-based resources and activities, meaningful and reciprocal relationships and a sense of belonging and participation in mainstream community, despite some challenges being faced. Participants' experiences also highlight the dynamic nature of social inclusion, the interaction between individuals and context and also the interaction between Simplican et al.'s (2015) two core life domains of Interpersonal Relationships and Community Participation. The following sections explore the impacts of MA Rugby in relation to other research and the implications of our findings for future inclusive sport initiatives.

\subsection{Impacts of MA Rugby}

MA Rugby appears to have benefits for all participants regardless of (dis)ability, as well as others involved through, for example, volunteering and refereeing. This supports previous research suggesting that beneficiaries of social inclusion initiatives extend beyond those with disabilities and that social inclusion improves lives for all involved (Lyras \& Peachey, 2011; Mahar, Cobigo, \& Stuart, 2013; Simplican et al., 2015).

Expanded social networks are highlighted by participants as key benefits of MA Rugby, in particular through enhancing social capital. Putnam defines social capital as 'networks, norms and social trust that can facilitate coordination and cooperation for mutual benefit' (1995, p. 66) and Collins expands this to suggest that personal social capital exists alongside communal social capital comprising individual skills and knowledge, self-confidence and supportive relationships (2004). Both are developed through MA Rugby. Other authors have identified 'bonding' and 'bridging' social capital where bonding is localised and emphasises strong, multi-functional ties and bridging encourages personal and community development through extending ties beyond personal and immediate networks (Darcy et al., 2014; Putnam, 2000; Woolcock, 2001). Again the development of both is evident through MA Rugby, supporting previous assertions that interaction through sport can lead to deep friendships that extend beyond the sporting context (Tonts, 2005) as well as expanding immediate, personal networks (Darcy et al., 2014; Putnam, 2000). Furthermore, these data support the dynamic and reinforcing relationship between social capital and personal development. The increased participation in the community and more developed social networks lead to improved self-confidence and social skills as well as the potential for more opportunities for further personal development for all participants and, in particular, for participants with learning disabilities (Darcy et al., 2014; Lawson, 2005; Wilson et al., 2016).

Our findings also support claims that sport can cultivate friendships across groups who do not generally interact due to differences in, for example, ethnicity, age, gender and (dis)ability (Skinner, Zakus, \& Cowell, 2008) and this can have broader implications in terms of shifting perceptions. SCOPE $(2013$, p. 14) highlighted that 'more everyday interactions....will increase understanding and acceptance of disabled people', and interaction between different groups is agreed to be a predictor of more positive attitudes (Brown \& Hewstone, 2005). This could be particularly critical in Italy where CENSIS data show that disability is still perceived by two out of three Italians as limitation of movement or physical impairment, which renders those with learning disabilities non-existent (CENSIS, 2014).

Hewstone (2015) suggests that perception and attitude shifts are more likely to occur when participants are of equal status, when the context demands stereotypes are challenged and when cooperation is required by ev- 
eryone involved, such as in a mainstream sports team context. Our findings reveal further contextual factors that impact whether broader benefits of sport initiatives aimed at inclusion across disabled and non-disabled participants are likely to be achieved. These are presented as a 'Wheel of Inclusion' in Figure 2. The following section details how the Wheel can be used to inform development of future sport initiatives with similar aims.

\subsection{Implications for Future Inclusive Sports Initiatives}

The Wheel of Inclusion comprises 8 sections, each of which correspond to a characteristic of sports initiatives which our data highlight as key to maximising benefits for all participants and to achieving broader social inclusion. The Wheel incorporates key, relevant terms from Simplican et al.'s (2015) model of inclusion as well as expanding on the model in the context of MA Rugby. Our data suggest that the key starting point of an inclu- sive sport initiative is the club structure, reflected in 'setting', 'frequency' and 'membership status'. Within that, the club environment, reflected in 'supportive environment' and 'exchange' facilitates the inclusive nature of the initiative. The 'advocacy' and 'level' sections reflect the individual participant's role in promoting inclusion through how involved they become and all these sections link to whether the development of 'social networks' takes place.

Our data highlight that a mainstream setting for MA Rugby is key to maximising benefits from inclusive sports such as shifting perceptions, increased social capital and personal development. These findings support previous research emphasising the benefits of mainstream inclusion settings for those with disabilities (Bates \& Davis, 2004) as well as for raising awareness about and challenging stigma attached to disability (Simplican et al., 2015). However, data highlight that mainstream settings also need to be supportive and welcoming in order to pro-

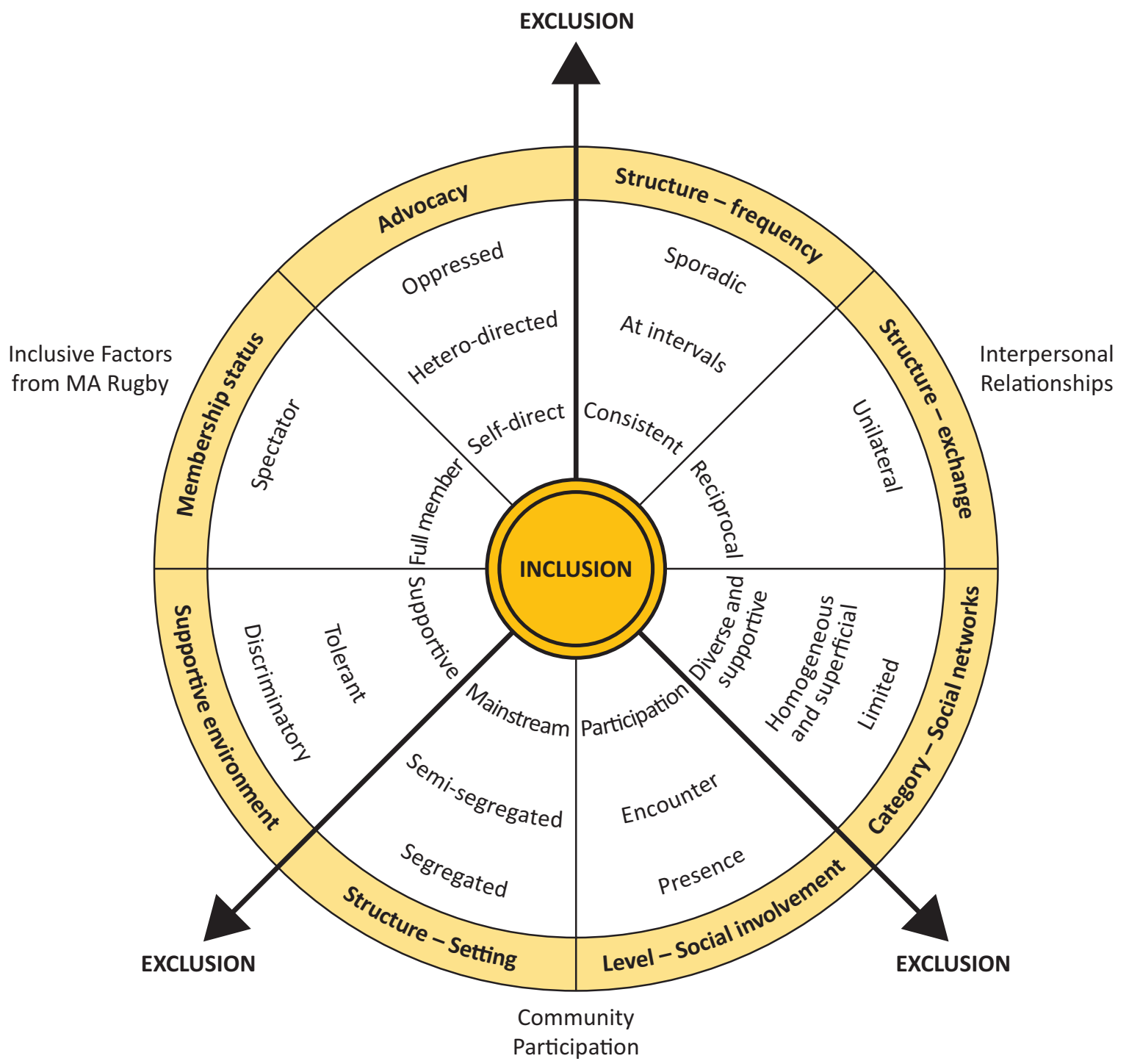

Figure 2. 'Wheel of Inclusion' incorporating key elements of Simplican et al.'s (2015) model of inclusion as well as expanding on the model in the context of MA Rugby. 
vide the same sense of belonging and safety that proponents of segregated settings for disabled people emphasise as important (Hall, 2010). In providing a supportive environment, MA Rugby removes some of the key barriers to participating in sport such as exposure to prejudice (Wilson et al., 2016), inadequate support from coaches and assistants (Darcy \& Dowse, 2013; Emerson, Hatton, Robertson, \& Baines, 2014) and lack of disability awareness (Darcy \& Dowse, 2013; EFDS, 2014). While having full membership of a Club and a mainstream Club location were reported by participants as having various benefits such as promoting equality, independence and sustainability, there could be concerns over whether this excludes some participants on the grounds of finance and transport issues, key barriers often cited as reducing participation in sports for many groups in society (Darcy \& Dowse, 2013; EFDS, 2014).

A further important aspect of MA Rugby clearly emerged as the self-advocacy disabled participants have in choosing to assume risks for themselves. This choice appears critical in fostering a sense of belonging, equality and empowerment, which are highlighted in previous research as key to inclusive initiatives (Van Asselt et al., 2015; Wilson et al., 2016) and overlap with the Sport for Development, community capacity and independent living literature in suggesting that social justice is also key for inclusive outcomes (Edwards, 2015; Perske, 1972). More fundamentally, the challenge of dominant discourse around what disabled people can and can't do through self-advocacy and participation in full-contact rugby could have significant impacts on societal understanding of disability (Goodley, 1997).

\section{Conclusions}

Given the complex nature of social inclusion and the interactions between context and the multi-faceted experiences of participants, it is clear a 'one-size fits all' solution for fostering social inclusion through sport is not appropriate. However, the MA Model demonstrates potential for contributing to both personal, club and communitylevel inclusion through enhanced social networks, personal development and shifts in perception, attitudes and behaviours. The 'Wheel of Inclusion' has been developed through data from both disabled and non-disabled participants and we argue it could therefore provide a useful basis for evaluating current inclusive sport initiatives and for designing new ones, with new sections of the Wheel evolving as identified. A useful next step for research would be to apply the Wheel to inclusive sport initiatives focusing on other sports and other traditionally marginalised groups in society, as well as to females and to individuals who may find the MA Sport setting more appealing, such as those returning to sport or those looking for social outcomes rather than competition. In addition, it would be valuable to situate the Wheel in the broader socio-political context to analyse the impacts of broader factors on inclusionary outcomes.

\section{Acknowledgements}

The authors wish to thank all participants for their contribution of time as well as their willingness to discuss their personal experiences of MA Rugby. We would also like to thank Dr. Angharad Beckett and Dr. Rachel Sandford for their input and guidance.

\section{Conflict of Interests}

Martino Corazza is the Founder and Director of IMAS.

\section{References}

Armour, K., Sandford, R., \& Duncombe, R. (2013). Positive youth development and physical activity/sport interventions: mechanisms leading to sustained impact. Physical Education and Sport Pedagogy, 18(3), 256-281.

Bailey, R., Armour, K., Kirk, D., Jess, M., Pickup, I., . . . \& BERA Physical Education. (2009). The educational benefits claimed for physical education and school sport: an academic review. Research Papers in Education, 24(1), 1-27.

Bates, P., \& Davis, F. A. (2004). Social capital, social inclusion and services for people with learning disabilities. Disability \& Society, 19(3), 195-207.

Brown, R., \& Hewstone, M. (2005). An integrative theory of intergroup contact. Advances in Experimental Social Psychology, 37, 255-343.

CENSIS. (2014). Diario della transizione/3. I disabili, i più diseguali nella crescita delle diseguaglianze sociali. Rome. Retrieved from http://www.censis.it/7? shadow_comunicato_stampa $=120959$

Cobigo, V., Ouellette-Kuntz, H., Lysaght, R., \& Martin, L. (2012). Shifting our conceptualization of social inclusion. Stigma Research and Action, 2(2), 75-84.

Collins, M. (2004). Sport, physical activity and social exclusion. Journal of Sports Sciences, 22(8), 727-740.

Darcy, S., \& Dowse, L. (2013). In search of a level playing field-The constraints and benefits of sport participation for people with intellectual disability. Disability \& Society, 28(3), 393-407.

Darcy, S., Maxwell, H., Edwards, M., Onyx, J., \& Sherker, S. (2014). More than a sport and volunteer organisation: Investigating social capital development in a sporting organisation. Sport Management Review, 17(4), 395-406.

EC. (2010). European Disability Strategy 2010-2020. European Commission. Retrieved from http://eurlex.europa.eu/LexUriServ/LexUriServ.do?uri=COM: 2010:0636:FIN:en:PDF

Edwards, M. B. (2015). The role of sport in community capacity building: An examination of sport for development research and practice. Sport Management Review, 18(1), 6-19.

EFDS. (2012). Understanding the barriers to participation in sport. Retrieved from: http://www.Irsport.org/up 
loads/understanding-barriers-to-participation-14.pdf EFDS. (2014). Talk to me: Understanding how to increase participation in sport and physical activity amongst disabled people in the UK. Retrieved from: www. efds.co.uk/assets/000/000/271/Talk_to_me_FINAL_ original.doc?1462896025

Emerson, E., Hatton, C., Robertson, J., \& Baines, S. (2014). Perceptions of neighbourhood quality, social and civic participation and the self rated health of British adults with intellectual disability: Cross sectional study. BMC Public Health, 14(1), 1252.

Goodley, D. (1997). Locating self-advocacy in models of disability: Understanding disability in the support of self-advocates with learning difficulties. Disability \& Society, 12(3), 367-379. doi:10.1080/ 09687599727227

Hall, E. (2010). Spaces of social inclusion and belonging for people with intellectual disabilities. Journal of Intellectual Disability Research, 54(s1), 48-57.

Hewstone, M. (2015). Consequences of diversity for social cohesion and prejudice: The missing dimension of intergroup contact. Journal of Social Issues, 71(2), 417-438.

ISTAT. (2010). La disabilità in Italia. II quadro della statistica ufficiale. Rome. Retrieved from http://www3. istat.it/dati/catalogo/20100513_00/arg_09_37_la_ disabilita_in_Italia.pdf

Kelly, L. (2011). 'Social inclusion' through sports-based interventions? Critical Social Policy, 31(1), 126-150.

Lawson, H. A. (2005). Empowering people, facilitating community development, and contributing to sustainable development: The social work of sport, exercise, and physical education programs. Sport, Education and Society, 10(1), 135-160.

Levermore, R. (2010). CSR for development through sport: Examining its potential and limitations. Third World Quarterly, 31(2), 223-241.

Levermore, R., \& Beacom, A. (2009). Sport and development: Mapping the field. Palgrave Macmillan.

Lyras, A., \& Peachey, J. W. (2011). Integrating sport-fordevelopment theory and praxis. Sport Management Review, 14(4), 311-326.

Mahar, A. L., Cobigo, V., \& Stuart, H. (2013). Conceptualizing belonging. Disability and Rehabilitation, 35(12), 1026-1032.

Miles, M. B., \& Huberman, A. M. (1994). Qualitative data analysis: A sourcebook. Beverly Hills: Sage Publications.

Perske, R. (1972). The dignity of risk and the MR. Mental Retardation, 10(1), 24-27.

Petitpas, A. J., Cornelius, A. E., Van Raalte, J. L., \& Jones, T. (2005). A framework for planning youth sport programs that foster psychosocial development. The Sport Psychologist, 19(1), 63-80.

Putnam, R. D. (1995). Bowling alone: America's declining social capital. Journal of Democracy, 6(1), 65-78.

Putnam, R. D. (2000). Bowling alone: America's declining social capital. In L. Crothers \& C. Lockhart (Eds.), Cul- ture and politics (pp. 223-234). New York: Palgrave Macmillan.

Rich, K. A., Misener, L., \& Dubeau, D. (2015). "Community cup, we are a big family": Examining social inclusion and acculturation of newcomers to Canada through a participatory sport event. Social Inclusion, 3(3), 129-141.

Rookwood, J., \& Palmer, C. (2011). Invasion games in war-torn nations: Can football help to build peace? Soccer \& Society, 12(2), 184-200.

SCOPE. (2013). Have the Paralympics improved the daily lives of disabled people? Retrieved from: http:// blog.scope.org.uk/2013/08/29/have-the-paralympics -improved-the-daily-lives-of-disabled-people

Simplican, S. C., Leader, G., Kosciulek, J., \& Leahy, M. (2015). Defining social inclusion of people with intellectual and developmental disabilities: An ecological model of social networks and community participation. Research in Developmental Disabilities, 38, 18-29.

Skinner, J., Zakus, D. H., \& Cowell, J. (2008). Development through sport: Building social capital in disadvantaged communities. Sport Management Review, 11(3), 253-275.

Spaaij, R., Magee, J., \& Jeanes, R. (2014). Sport and social exclusion in global society. London: Routledge.

Sport England. (2016). Active people survey. Retrieved from: https://www.sportengland.org/media/10745/ 1x30_overall_factsheet_aps10q2.pdf

Sugden, J. (2006). Teaching and playing sport for conflict resolution and co-existence in Israel. International Review for the Sociology of Sport, 41(2), 221-240.

Swain, F., French, S., Barnes, C., \& Thomas, C. (2014). Disabling barriers: Enabling environments (3rd. ed.). London: Sage.

Tonts, M. (2005). Competitive sport and social capital in rural Australia. Journal of Rural Studies, 21(2), 137-149.

UN. (2006). Convention on the rights of persons with disabilities and optional protocol. New York: United Nations. Retrieved from http://www.un.org/ disabilities/convention/conventionfull.shtml

UN. (2015). Declaration of the 2030 agenda for sustainable development, resolution adopted by the General Assembly on 25th September 2015. Retrieved from http://www.un.org/en/ga/search/view_doc.asp?sym bol=A/RES/70/1

Van Asselt, D., Buchanan, A., \& Peterson, S. (2015). Enablers and barriers of social inclusion for young adults with intellectual disability: a multidimensional view. Journal of Intellectual and Developmental Disability, 40(1), 37-48.

Wendel, M. L., Burdine, J. N., McLeroy, K. R., Alaniz, A., Norton, B., \& Felix, M. R. J. (2009). Community capacity: Theory and application. Emerging Theories in Health Promotion Practice and Research, 2, 277-302.

Wickman, K. (2015). Experiences and perceptions of young adults with physical disabilities on sports. Social Inclusion, 3(3), 39-50. 
Wilson, N. J., Jaques, H., Johnson, A., \& Brotherton, M. L. (2016). From social exclusion to supported inclusion: Adults with intellectual disability discuss their lived experiences of a structured social group. Journal of Applied Research in Intellectual Disabilities, 112. doi:10.1111/jar.12275
Woolcock, M. (2001). The place of social capital in understanding social and economic outcomes. Canadian journal of policy research, 2(1), 11-17.

\section{About the Authors}

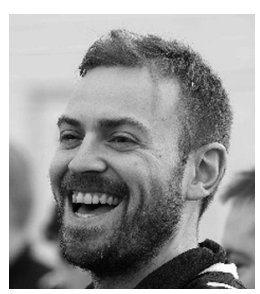

Martino Corazza holds an MA in Disability Studies from the University of Leeds and is passionate about rugby and lifelong education. He has been working for many years in further and adult education as a specialist tutor, as well as in European projects aiming to promote international co-operation, active citizenship and personal development. Martino is the founder and Director of International Mixed Ability Sports (IMAS), a not for profit organisation promoting social inclusion through mainstream and non adapted sports.

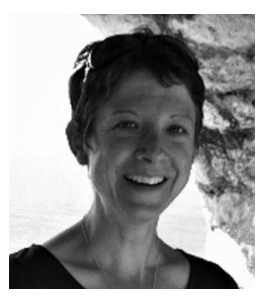

Jen Dyer (PhD) is a Lecturer in Sustainability at the University of Leeds. Her research is interdisciplinary and focuses on using participatory methods to holistically evaluate initiatives in a variety of contexts and around a range of topics such as natural resource management, student engagement and, more recently, social inclusion. Jen prioritises engaging relevant stakeholders at all stages in her research in order to increase the relevance and impact of research findings. 